\title{
Pengaruh Sensitivitas Suhu dengan Metode Couple-Mode terhadap Fiber Bragg Grating Fiber Optik
}

\author{
Nasrulloh $^{1 *)}$, Ary Syahriar ${ }^{2)}$, Rizki Noor Prasetyono ${ }^{3)}$ \\ 1,3) Program Studi Teknik Elektro, Universitas Peradaban, Bumiayu \\ ${ }^{2)}$ Universitas Al-Azhar Indonesia, Tangerang Selatan \\ * email: arul.ste@gmail.com
}

\begin{abstract}
Fiber Bragg Grating (FBG) is an optical fiber that has a periodic variation of refractive index. The FBG wavelength will shift if the lattice section changes the distance due to changes in temperature received by the optical fiber. In this research, the effect of changes in temperature sensitivity on FBG is solved and explained using the Couple-Mode Theory method. The coupled-mode theory is numerically integrated with the Transfer Matrix method to reach the final equation of the effect of temperature in FBG. Simulations and analyses using MatLab software were carried out to get an effective discussion. The results of the research show that temperature changes affect wavelength changes. In addition, an increase in temperature will affect the increase in the sensitivity of the FBG. This characteristic provides an opportunity to produce a filter, sensor, or other application for the enhancement of optical fiber and photonics technology.
\end{abstract}

Keywords - Coupled-mode theory, Fiber Bragg grating, refractive index, temperature

\section{Pendahuluan}

Lebih dari 20 tahun terakhir, terdapat dua revolusi produk utama yang mengambil alih peranan teknologi pada pertumbuhan industri fotonik, yaitu opto-elektronik dan komunikasi serat optik. Industri komunikasi serat optik telah benar-benar merevolusi industri telekomunikasi dengan menyediakan koneksi atau sambungan jaringan telekomunikasi yang berkinerja lebih tinggi dan lebih handal dengan biaya bandwidth yang lebih rendah. Revolusi ini membawa manfaat produksi dalam jumlah yang tinggi bagi pengguna komponen elektronika dan informasi yang benar-benar berkualitas tinggi dan terbuat dari serat kaca. Sejalan dengan perkembangan ini, teknologi sensor serat optik telah menjadi teknologi utama yang digunakan yang terkait dengan industri komunikasi opto-elektronik \& serat optik.

Optik adalah cabang ilmu fisika yang mendeskripsikan perilaku dan sifat cahaya serta interaksi cahaya dengan materi. Optik adalah alat yang paling berguna yang digunakan dalam sistem telekomunikasi untuk mengalihkan teknologi lama dengan teknologi baru [1]. Sejak penemuan FBG (Fiber Bragg Grating) dikaitkan dengan karya Hill et al di Pusat Riset Komunikasi di Kanada pada tahun 1978, FBG telah menjadi perangkat optik yang sangat menarik dalam sistem komunikasi optik berkinerja tinggi [2]. FBG telah muncul sebagai komponen penting dalam aplikasi yang luas. Manfaat FBG membuatnya menarik untuk aplikasi lain juga. Dalam sistem telekomunikasi, FBG digunakan untuk kompensasi dispersi dalam sistem transmisi serat optik, filter demultiplexing untuk sistem multiplexing divisi panjang gelombang, dan kisi-kisi periode panjang untuk mendapatkan perataan penguat serat yang menggunakan doping erbium [3]. FBG juga merangsang pertumbuhan aplikasi serat optik di luar telekomunikasi, seperti konversi frekuensi nonlinier, spektroskopi, dan penginderaan jauh.

Salah satu aplikasi dari modifikasi serat optik ini adalah sensor. Aplikasi sensor yang yang paling sederhana adalah dengan memvariasikan intensitas cahaya, karena hanya memerlukan sumber dan detektor sederhana $[4,5]$. Contoh dari aplikasi sensor ini adalah 
pengukuran suhu di dalam mesin jet pesawat dengan menggunakan serat optik untuk mengirimkan radiasi ke pirometer radiasi yang terletak di luar mesin. Selain itu, Sensor ekstrinsik juga dapat digunakan dengan cara yang sama untuk mengukur suhu internal transformator listrik, di mana medan elektromagnetik ekstrim yang ada membuat teknik pengukuran lain tidak mungkin dilakukan. Penggunaan sensor ekstrinsik ini antara lain untuk mengukur getaran, rotasi, perpindahan, kecepatan, percepatan, torsi, dan puntiran [6]. Keluaran dari modifikasi kisi-kisi bragg pada serat optik inilah yang menarik ilmuwan untuk pengembangan lebih lanjut.

Penelitian sebelumnya seperti pada Yuliana dkk [7] menggunakan FBG (Fiber Bragg Grating) pada simulasi menentukan panjang gelombang dalam rentang $C$-Band. Khlaifi dkk [8] juga menambahkan bahwa FBG memerlukan deteksi batas untuk membedakan suhu, regangan dan tekanan menggunakan kisi serat Bragg. Penelitian Pang dkk [9] melakukan penelitian pengukuran suhu dan indeks bias pada kisi serat Bragg untuk menentukan sesitivitas dan linearitas dari FBG tersebut.

Perubahan suhu adalah salah satu cara untuk merubah atau memodifikasi FBG agar bisa digunakan sesuai kebutuhan. Penjelasan pengaruh perubahan suhu terhadap FBG belum banyak diteliti, bahkan diaplikasikan terhadap dunia industri. Hal ini dikarenakan pengaruh suhu terhadap FBG biasanya terjadi dalam skala yang kecil dan perubahan performa yang tidak signifikan. Pada penelitian ini, akan diterangkan secara persamaan matematika dan simulasi grafik untuk menganalisi perubahan suhu terhadap karakteristik FBG. Hal ini dilakukan untuk melihat perubahan kinerja yang terjadi pada FBG dan bagaimana merekayasa FBG agar bisa digunakan untuk setiap aplikasi teknologi serat optik dengan optimal.

\section{Dasar Teori}

Dalam sistem telekomunikasi, FBG digunakan untuk kompensasi dispersi dalam sistem transmisi serat optik, filter demultiplexing untuk sistem multiplexing divisi panjang gelombang, dan kisi-kisi periode panjang untuk mendapatkan perataan penguat serat yang menggunakan doping erbium [10]. FBG juga merangsang pertumbuhan aplikasi serat optik di luar telekomunikasi, seperti konversi frekuensi nonlinier, spektroskopi, dan penginderaan jauh. Gambar 1 menunjukkan fungsionalitas kisi periode dalam FBG, dan bagaimana kisi Bragg bekerja dalam komunikasi serat optik.

Perkembangan teknologi serat optik banyak digunakan sebagai sensor untuk mengukur regangan, suhu, tekanan, dan besaran lain dengan memodifikasi serat optik. Perubahan dan modifikasi ini dilakukan agar kuantitas yang akan diukur memodulasi intensitas, fasa, polarisasi, panjang gelombang, atau waktu transit cahaya dalam serat tersebut [11].

Pada dasarnya, FBG didasarkan pada prinsip refleksi Bragg. Ketika cahaya merambat melalui daerah indeks bias yang lebih tinggi dan lebih rendah secara berkala bergantian, maka sebagian cahaya dipantulkan pada setiap antarmuka antar daerah tersebut. Jika jarak antara daerah-daerah tersebut sedemikian rupa sehingga semua refleksi parsial bertambah dalam fase ketika perjalanan cahaya antara dua refleksi merupakan jumlah integral panjang gelombang, maka refleksi total dapat tumbuh hampir $100 \%$, bahkan jika refleksi per bagian sangat kecil. Sesuai Gambar 2, kondisi refleksi tinggi dikenal dengan istilah Bragg. FBG terdiri dari modulasi indeks pembiasan berkala di sepanjang inti serat optik. 


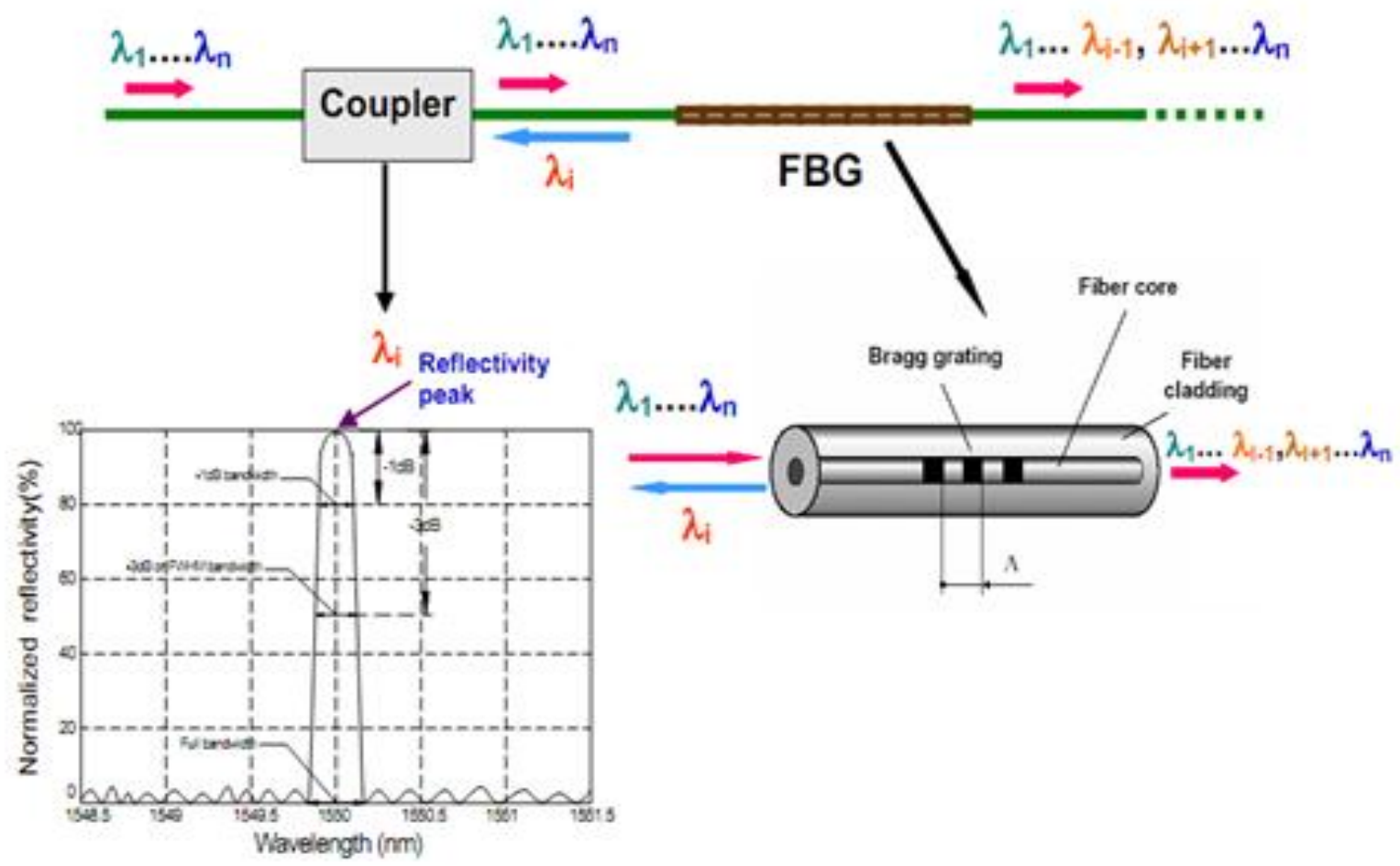

Gambar 1. Struktur fiber bragg grating (FBG) dan karakteristiknya terhadap panjang gelombang $1550 \mathrm{~nm}[2]$
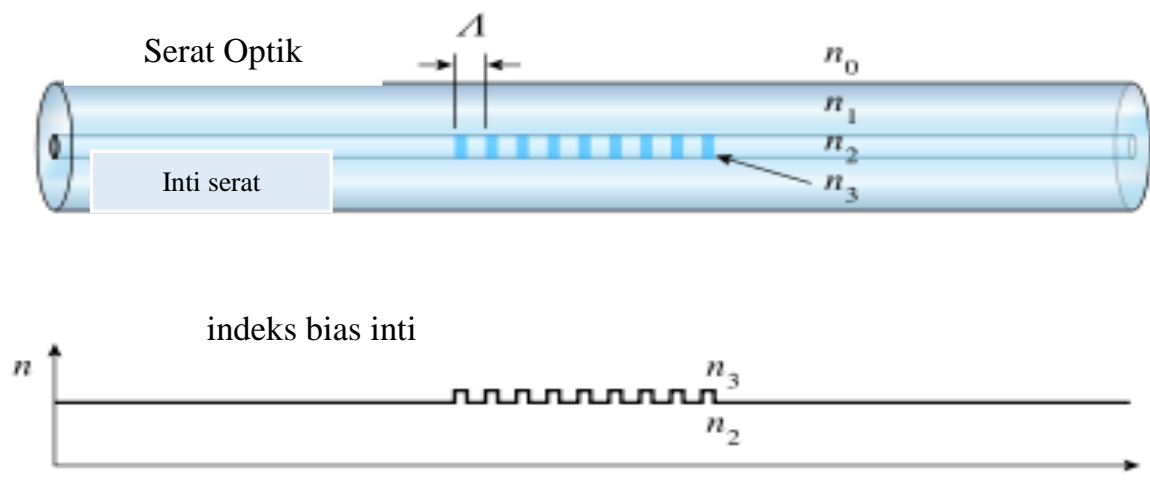

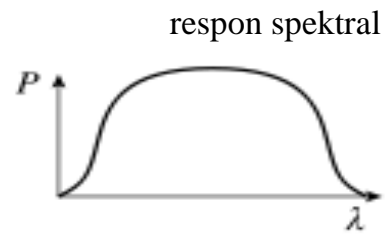

Daya masukan

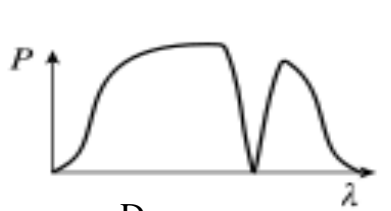

Daya yang ditransmisikan

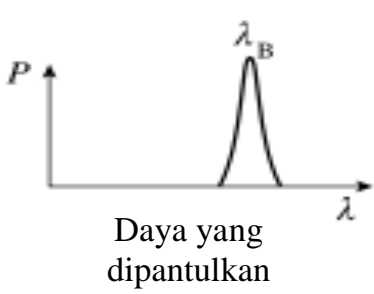

dipantulkan

Gambar 2. Karakteristik FBG pada serat optik dan daya yang dipancarkan [2]

Penurunan rumus merupakan langkah awal untuk memahami parameter dan karakteristik sensitivitas suhu. Untuk mendapatkan persamaan akhir dari FBG, maka digunakan teori Couple-mode yang merupakan salah satu alat yang penting untuk menggambarkan fenomena yang terjadi pada FBG. Persamaan ini dapat ditemukan dengan menganggap bahwa medan listrik transversal dapat dinyatakan sebagai kombinasi gelombang 
perjalanan maju dan mundur, sehingga didapatkan Persamaan $1[10,12]$ sebagai berikut.

$$
\vec{E}_{t}(r, \theta, z, t)=\sum_{v m}\left[A_{v m}(z) e^{j \beta_{v m} z}+B_{v m}(z) e^{-j \beta_{v m} z}\right] \vec{b}_{v m t}(r, \theta) e^{-j \omega t}
$$

Di mana, $\boldsymbol{A}_{\boldsymbol{v} \boldsymbol{m}}(\mathbf{z})$ dan $\boldsymbol{B}_{\boldsymbol{v m}}(\mathbf{z})$ adalah amplitudo yang bervariasi secara perlahan dari mode $\mathrm{v}_{\mathrm{m} \text { th }}$ yang masing-masing bergerak ke arah depan dan belakang. $\omega$ adalah frekuensi sudut propagasi dan $\beta$ adalah konstanta propagasi berdasarkan Persamaan 2.

$$
\beta=2 \pi n_{e f f} / 2
$$

di mana $\boldsymbol{n}_{\text {eff }}$ adalah indeks bias efektif dari mode tertentu.

Dari persamaan awal gelombang yang dijelaskan di Persamaan (1), maka persamaan selanjutnya diturunkan berdasarkan metode Matriks Transfer untuk memudahkan penurunan persamaan matematika. FBG diilustrasikan sebagai kisi-kisi yang membentuk persamaan tertentu untuk kemudian dijelaskan dengan matriks transfer.

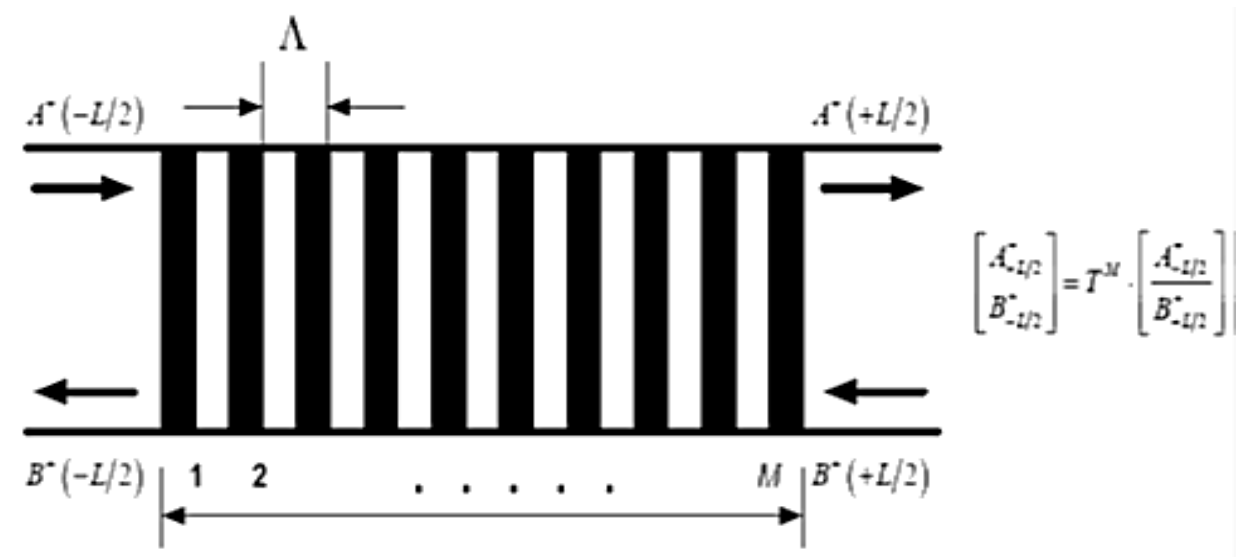

Gambar 3. Ilustrasi simulasi kisi menggunakan metode matriks transfer [2]

Dari ilustrasi Gambar 3 di atas, maka propagasi masing-masing bagian k dijelaskan oleh matriks transfer $\mathbf{T}_{\mathbf{k}}$ yang dinyatakan dalam Persamaan (3) di bawah ini [12, 13]:

$$
\left(\frac{A_{k}^{+}}{B_{k}^{+}}\right)=T_{k}\left(\frac{A_{k-1}^{+}}{B_{k-1}^{+}}\right)
$$

Di mana Matriks Transfer $\mathbf{T}_{\mathbf{k}}$ dinyatakan dengan Persamaan (4) berikut.

$$
T_{k}=\left(\begin{array}{cc}
\cosh \left(\gamma_{B} d z\right)-j \frac{\sigma^{\prime}}{\gamma_{B}} \sinh \left(\gamma_{B} d z\right) & -j \frac{\kappa}{\gamma_{B}} \sinh \left(\gamma_{B} d z\right) \\
j \frac{\kappa}{\gamma_{B}} \sinh \left(\gamma_{B} d z\right) & \cosh \left(\gamma_{B} d z\right)+j \frac{\sigma^{\prime}}{\gamma_{B}} \sinh \left(\gamma_{B} d z\right)
\end{array}\right)
$$

Dari persamaan matriks transfer, didapatkan persamaan reflektifitas kisi dengan amplitudo modulasi konstan dan periode yang konstan, sehingga kita dapatkan Persamaan (5) sebagai berikut. 


$$
R=\frac{k^{2} \sin h^{2}(s l)}{\delta^{2} \sinh ^{2}(s l)+s^{2} \cosh (s l)}
$$

Koefisien transmisi daya berkaitan dengan koefisien refleksi melalui hukum kekekalan energi, sehingga hukum kekelan energi masu pada Persamaan (6).

$$
R(\lambda)+T(\lambda)=1
$$

Indeks bias efektif pada inti serat optik dan periode kisi menentukan pusat panjang gelombang pada serat optik, sehingga perubahan serat dengan regangan dan suhu akan mempengaruhi indeks bias inti [11]. Pergeseran panjang gelombang pusat kisi Bragg akibat perubahan regangan dan suhu dapat dilihat pada Persamaan (7) berikut.

$$
\Delta \lambda_{B}=2\left(\Lambda \frac{\partial n_{e f f}}{\partial l}+n_{e f f} \frac{\partial \Lambda}{\partial l}\right) \Delta l+2\left(\Lambda \frac{\partial n_{e f f}}{\partial T}+n_{e f f} \frac{\partial \Lambda}{\partial T}\right) \Delta T
$$

Di mana:

$\Delta \lambda_{B}=$ perbedaan panjang gelombang dari panjang gelombang kisi

$\Lambda \quad=$ periode kisi

$n_{\text {eff }}=$ indeks bias efektif

$\Delta l \quad=$ perubahan panjang kisi

$\Delta T=$ perubahan suhu, dengan $\mathrm{T}$ adalah suhu.

Perubahan panjang kisi yang disebabkan oleh ragangan pada serat juga akan mempengaruhi periode kisi dan indeks bias yang diinduksi regangan-optik. Regangan ini dipengaruhi juga oleh perubahan temperatur yang berpengaruh terhadap material serat optik jika temperatur berubah dari suhu awalnya [14]. Biasanya, kenaikan suhu membuat ion-ion material bergerak lebih cepat daripada penurunan suhu. Pada penerapan FBG, terjadi pergeseran pusat panjang gelombang FBG karena muai panas mengubah periode kisi dan indeks bias. Jika suhu naik, periode kisi akan lebih lama dan indeks bias akan lebih lama berada pada posisi awal dari sebelumnya. Pergeseran panjang gelombang akibat perubahan suhu $(\Delta T)$ dapat diketahui dari Persamaan (8) berikut.

$$
\Delta \lambda_{\mathrm{B}(\mathrm{t})}=\lambda_{\mathrm{B}}(\alpha+\zeta) \Delta \mathrm{T}
$$

Keterangan:

$\alpha=\left(\frac{1}{\Delta}\right)\left(\frac{\partial \Lambda}{\partial \mathrm{T}}\right)=$ koefisien muai panas

$\zeta=\left(\frac{1}{\mathrm{n}_{\text {eff }}}\right)\left(\frac{\partial \mathrm{n}_{\text {eff }}}{\partial \mathrm{T}}\right)=$ koefisien termo-optik

$\Lambda=$ periode kisi

$\Delta \mathrm{T}=$ perubahan suhu

Nilai $\alpha$ merupakan koefisien pemuaian serat optik dengan nilai $0,55 \times 10^{-6}{ }^{0} \mathrm{C}^{-1}$ untuk silika dan $\zeta$ merupakan koefisien termo optic dengan nilai $8,6 \times 10^{-6}{ }^{0} \mathrm{C}^{-1}$ untuk serat inti silika yang didoping dengan material germanium. Dari Persamaan (6), maka sensitivitas yang diharapkan pada FBG pada panjang gelombang $\sim 1550 \mathrm{~nm}$ adalah sekitar $13,7 \mathrm{pm} /{ }^{\circ} \mathrm{C}$.

Pergeseran panjang gelombang dapat diketahui dengan menghitung selisih antara daya keluaran yang ditampilkan dan daya input yang diberikan, sehingga perubahan temperatur dan daya keluaran referensi dapat dinyatakan dalam Persamaan (9) berikut. 


$$
\Delta P_{0}=18,7 \exp \left[-0,111\left(\Delta \lambda_{B, 0}\right)^{2}\right]-18,7 \exp \left[-0,111\left(\Delta \lambda_{B, 1}\right)^{2}\right]
$$

Di mana $\Delta \lambda B, 0$ adalah panjang gelombang Bragg pada keadaan referensi dan $\Delta \lambda B, 1$ adalah panjang gelombang Bragg pada pemberian variasi temperatur.

\section{Metode Penelitian}

Penelitian ini dilakukan dengan mencari solusi matematika sehingga didapatkan persamaan akhir untuk pengaruh suhu terhadap FBG. Dari persamaan akhir, dilakukan simulasi karakteristik perubahan suhu terhadap FBG menggunakan software MatLab. Grafik yang didapatkan dari hasil simulasi kemudian dianalisis untuk mendapatkan kesimpulan penelitian. Pengolahan data dilakukan dengan memasukkan parameter-parameter berdasarkan Persamaan (8) dan (9) ke dalam coding MatLab untuk mendapatkan grafik yang diinginkan. Perubahan parameter suhu dilakukan dengan perubahan setiap $5{ }^{\circ} \mathrm{C}$. Analisis dilanjutkan dengan pengaruh perubahan suhu terhadap pusat daya reflektivitas dari panjang gelombang serat optik. Dan analisis terakhir adalah analsis terkait pengaruh perubahan suhu terhadap indeks bias. Secara umum, metode penelitian menggunakan alur sebagai berikut.

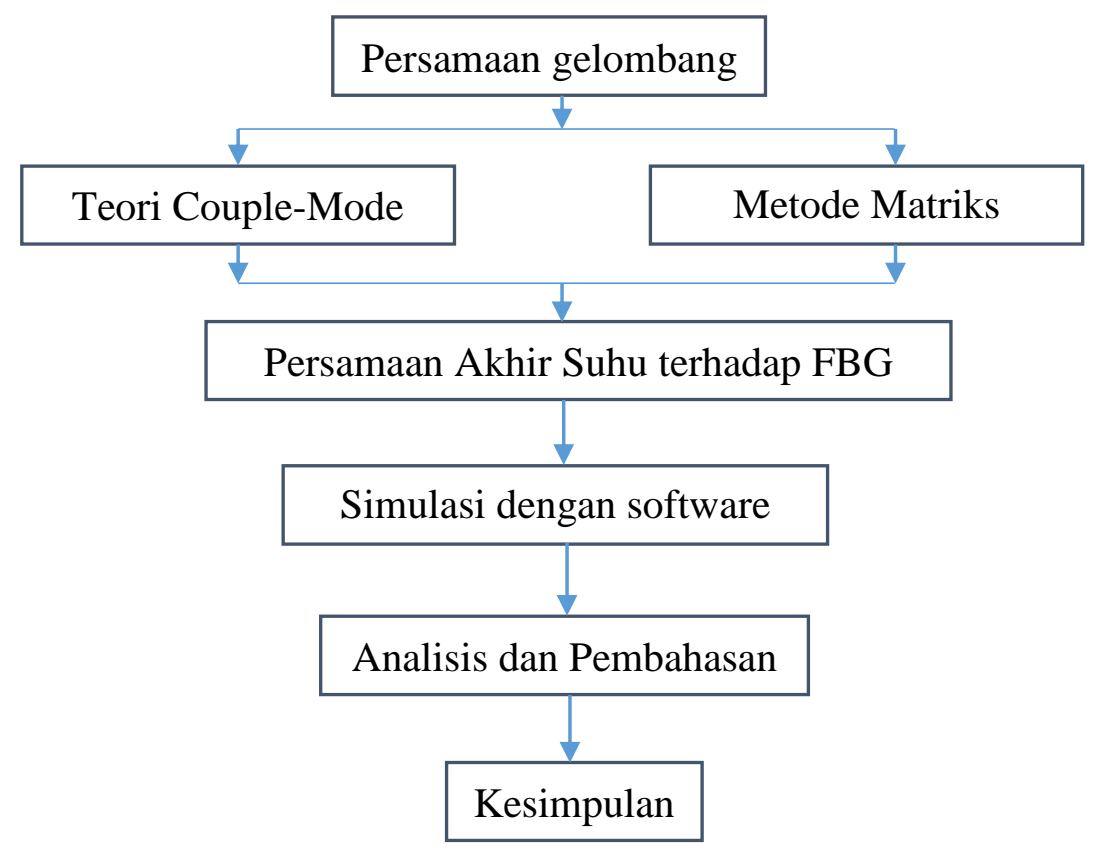

Gambar 4. Diagram alir penelitian

\section{Hasil dan Pembahasan}

Berdasarkan Persamaan (8) dan (9), maka dilakukan simulasi pergeseran panjang gelombang pusat FBG sebagai fungsi suhu. Biasanya, suhu memiliki pengaruh yang kuat pada sinyal FBG, sehingga pengukuran regangan yang tepat hanya dapat ditingkatkan dengan suhu yang sesuai [15]. Hasil simulasi dapat dilihat pada Gambar 5 di bawah ini. 


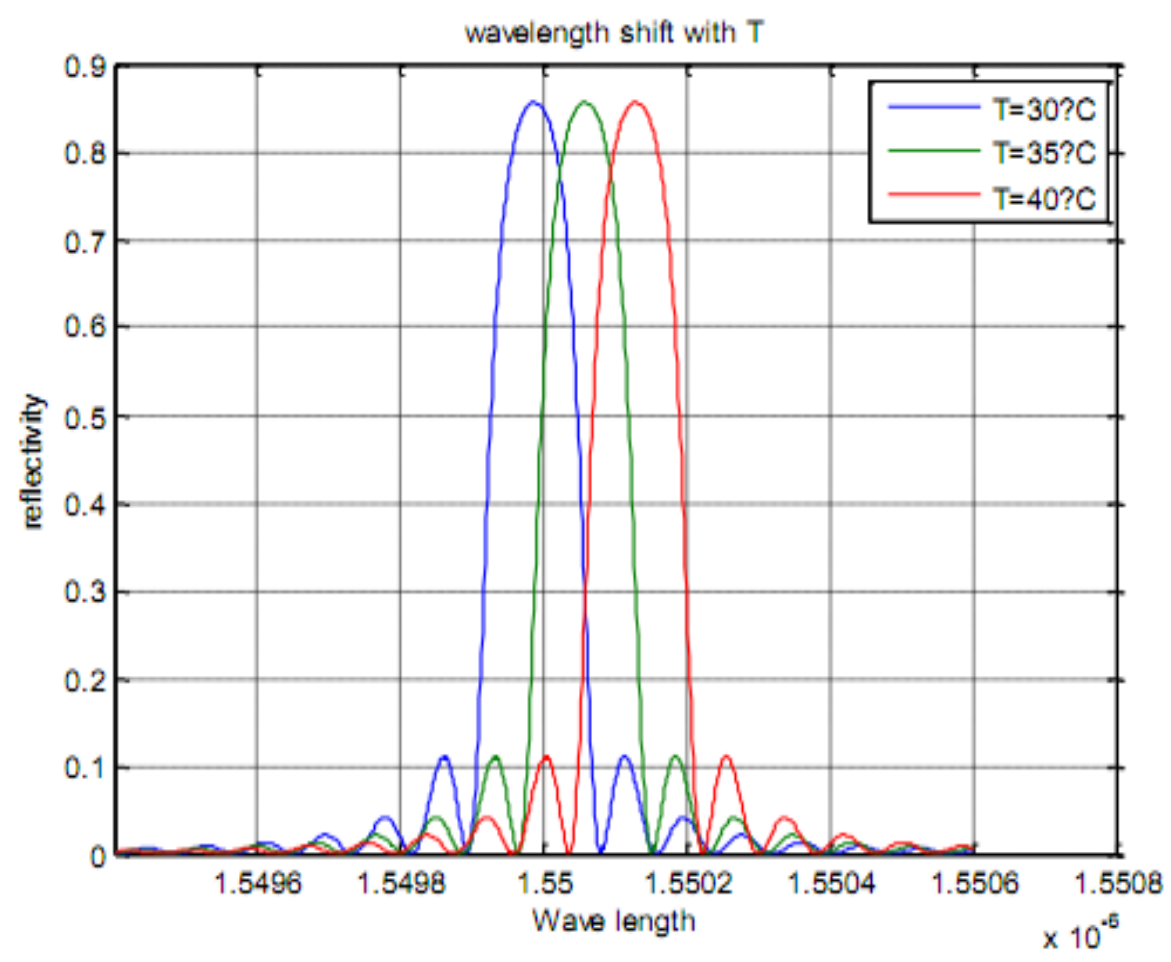

Gambar 5. Spektrum menunjukkan pergeseran panjang gelombang dengan temperatur yang bervariasi

Gambar 5 merepresentasikan pengaruh perubahan temperatur terhadap perubahan panjang gelombang berdasarkan daya pantulan puncak yang diterima. Dengan meningkatkan suhu pada FBG, maka pusat panjang gelombang akan bergeser ke nilai panjang gelombang yang lebih besar walaupun tetap memiliki nilai daya pantulan puncak yang sama. Oleh karena itu, dengan menyesuaikan suhu yang dipancarkan pada FBG maka total pergeseran panjang gelombang dapat disesuaikan dengan kebutuhan atau rekayasa yang dikehendaki. Tujuan dari pergeseran daya pantulan puncak panjang gelombang ini adalah untuk menghasilkan panjang gelombang yang presisi sesuai dengan aplikasi yang digunakan [16]. Dengan menerapkan temperatur yang lebih tinggi pada kisi Bragg, panjang gelombang akan bergeser lebih besar di area pusat panjang gelombang sehingga bisa menggeser struktur cacat pada serat optik dari $1550 \mathrm{~nm}$ ke panjang gelombang lain seperti $1551 \mathrm{~nm}$ atau $1552 \mathrm{~nm}$ tergantung pada seberapa besar kenaikan temperatur. Dengan menambahkan suhu yang lebih tinggi sekitar $50 \mathrm{C}$, panjang gelombang pusat akan bergeser sekitar $1 \mu \mathrm{m}$.

Dengan menerapkan formulasi $\Delta \lambda_{\mathrm{B}(\mathrm{t})}=\lambda_{\mathrm{B}}(\alpha+\zeta) \Delta$ korelasi yang jelas antara suhu dan panjang gelombang direpresentasikan pada Gambar 6 sebagai berikut. 


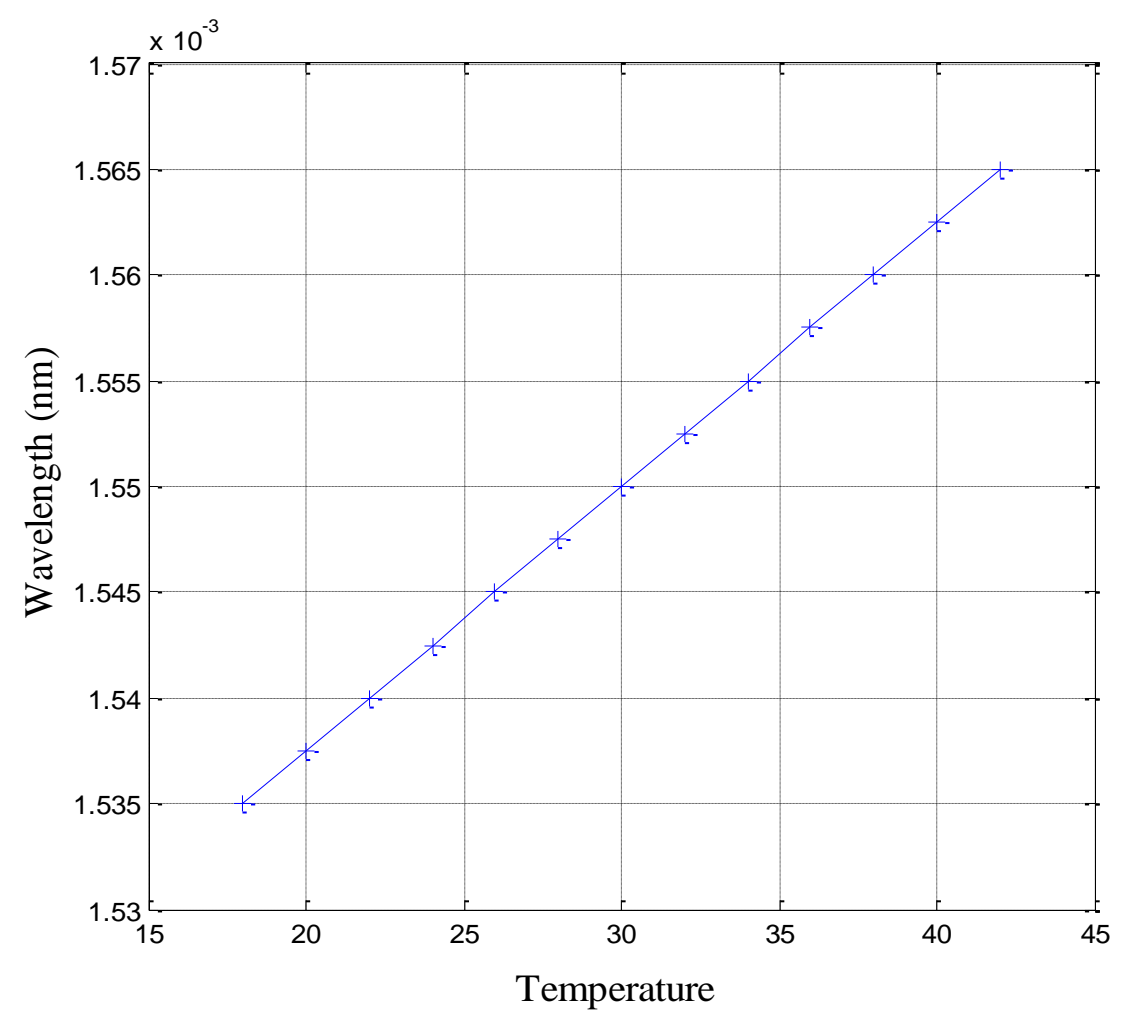

Gambar 6. Grafik perubahan suhu vs panjang gelombang

Gambar 6 menunjukkan hubungan antara perubahan suhu terhadap pergeseran panjang gelombang. Semakin tinggi suhu yang diaplikasikan pada FBG, maka pergeseran nilai panjang gelombang akan semakin besar. Meskipun pergeseran berada pada satuan mikrometer, tetapi kenaikan suhu yang signifikan akan merubah panjang gelombang yang berada pada puncak daya pantulan. Maka aplikasi serat optik yang beroperasi pada panjang gelombang $1550 \mathrm{~nm}$, perlu dilakukan penyesuaian suhu agar panjang gelombang ini tidak bergeser dan kinerja serat optik terutama pada FBG bisa bekerja dengan optimal.

Untuk melihat lebih jauh hubungan antara pengaruh perubahan suhu pada FBG, maka dilakukan simulasi hubungan indeks bias terhadap fungsi suhu dalam ${ }^{0} \mathrm{C}$ yang ditunjukkan pada Gambar 7. 


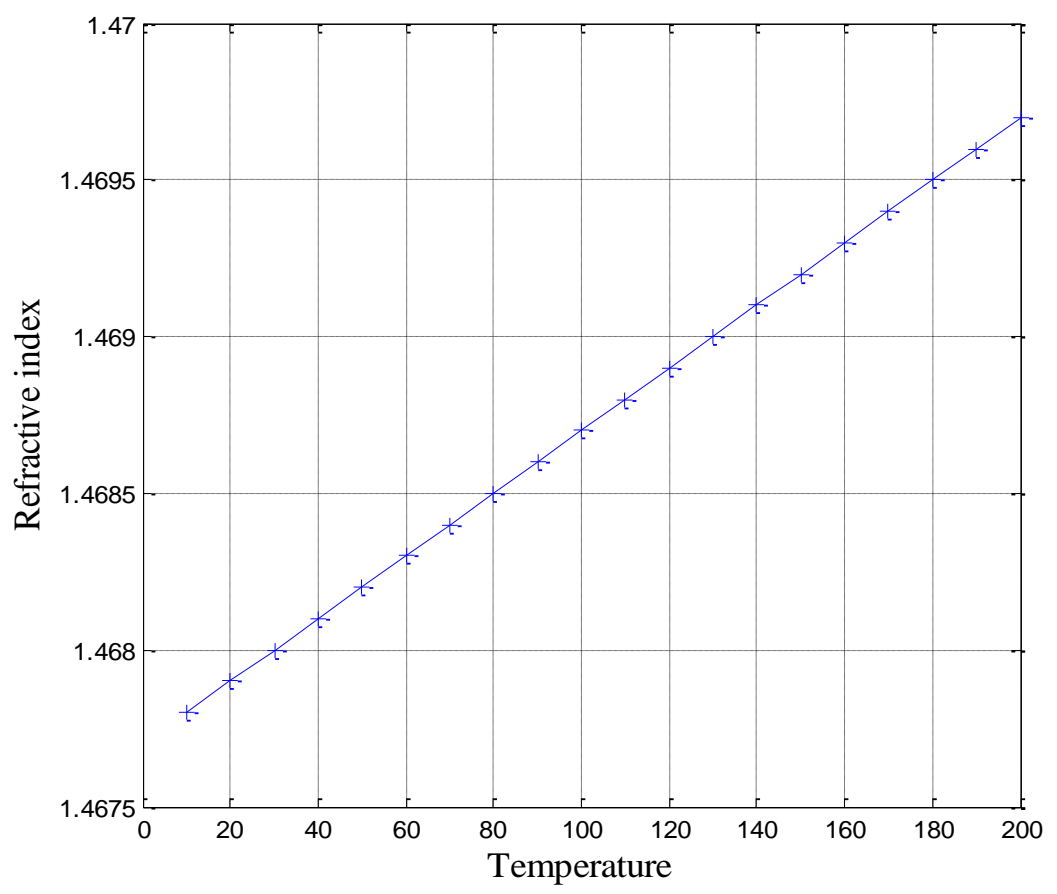

Gambar 7. Grafik hubungan Indeks bias sebagai fungsi suhu dalam 0C

Nilai indeks bias akan semakin meningkat seiring dengan peningkatan suhu pada FBG. Karakteristik indeks bias ini memberikan peluang untuk meningkatkan fungsi FBG ataupun serat optik kepada aplikasi yang lebih maju seperti filter, sensor, atau aplikasi yang berhubungan dengan sistem komunikasi. Fenomena ini dikenal juga dengan efek optik termal. Efek optik termal adalah fenomena di mana indeks bias suatu zat berubah dengan suhu. Pada kaca silika, efek ini ditandai dengan peningkatan indeks bias seiring kenaikan suhu.

\section{Kesimpulan}

Dalam FBG, suhu memiliki pengaruh yang penting. Hal itu tergantung kepada aplikasi di mana FBG ini akan digunakan. Berdasarkan penurunan rumus dan simulasi, disimpulkan bahwa hubungan peningkatan suhu dengan panjang gelombang adalah linier. Selain itu, suhu yang lebih tinggi dapat menyebabkan pergeseran panjang gelombang tetapi tidak mengubah daya pantul puncak. Peningkatan suhu berarti merubah pergeseran panjang gelombang walaupun dengan nilai perubahan yang kecil. Perubahan indeks bias dan suhu, dapat meningkatkan sensitivitas pada FBG sehingga menjadikan FBG sebagai filter, atau sensor sebagai aplikasi elektronik yang lebih baik. Penelitian terkait hubungan FBG dan perubahan suhu perlu dikembangkan lebih lanjut. Penelitian ini akan mendapatkan hasil yang lebih baik dan lebih terpercaya apabila bisa dilakukan uji lapangan sebagai perbandingan hasil antara hasil simulasi dengan hasil uji. Perbandingan hasil ini akan memberikan informasi yang lebih komprehensif untuk penelitian pada level berikutnya.

\section{Daftar Pustaka}

[1] Juraszek, J., \& Antonik-Popiołek, P. (2021). Fibre Optic FBG Sensors for Monitoring of the Temperature of the Building Envelope. Materials, 14(5), 1207.

[2] DeCusatis, C. (Ed.). (2013). Handbook of fiber optic data communication: a practical guide to optical networking. Academic Press.

[3] Murianti, D., Prakoso, T., \& Sofwan, A. (2018). FBG (Fiber Bragg Grating) Untuk DWDM (Dense Wavelength Division Multiplexing). Transient: Jurnal Ilmiah Teknik 
Elektro, 7(1), 77-82.

[4] Molardi, C. et al. (2019). Fiber Bragg grating (FBG) sensors in a high-scattering optical fiber doped with $\mathrm{MgO}$ nanoparticles for polarization-dependent temperature sensing. Applied Sciences, 9(15), 3107.

[5] Widasari, E. R., Pramono, S. H., \& Purnomo, M. F. E. (2013). Analisis Penerapan Optical Add-Drop Multiplexer (OADM) Menggunakan Fiber Bragg Grating (FBG) pada Teknik Dense Wavelength Division Multiplexing (DWDM). Jurnal Mahasiswa TEUB, 1(2).

[6] Putri, S. E., \& Harmadi, H. (2017). Rancang Bangun Sistem Pengukuran Frekuensi Getaran Akustik pada Speaker Piezoelektrik Menggunakan Sensor Serat Optik. Jurnal Fisika Unand, 6(1), 47-52.

[7] Sari, Y. P., Hambali, A., \& Pambudi, A. D. (2015). Simulasi Dan Analisis Optical Add Drop Multiplexer (oadm) Menggunakan Fiber Bragg Grating (fbg) Pada Link Long Haul. eProceedings of Engineering, 2(2).

[8] Khlaifi, H., Zrelli, A., \& Ezzedine, T. (2021). Optical fiber sensors in border detection application: Temperature, strain and pressure distinguished detection using fiber Bragg grating and fluorescence intensity ratio. Optik, 229, 166257.

[9] Pang, B., Gu, Z., Ling, Q., Wu, W., \& Zhou, Y. (2020). Simultaneous measurement of temperature and surrounding refractive index by superimposed coated long period fiber grating and fiber Bragg grating sensor based on mode barrier region. Optik, 220, 165136.

[10] A. Ghatak and K. Thyagarajan. (2013). "Introduction: The fiber optics revolution," in Introduction to fiber optics, 2013.

[11] Mohammad, N., Szyszkowski, W., Zhang, W. J., Haddad, E. I., Zou, J., Jamroz, W., \& Kruzelecky, R. (2004). Analysis and development of a tunable fiber Bragg grating filter based on axial tension/compression. Journal of Lightwave Technology, 22(8), 2001.

[12] Sukhoivanov, I. A., \& Guryev, I. V. (2009). Photonic crystals: physics and practical modeling (Vol. 152). Springer.

[13] K. C. Chuang, Z. Q. Zhang, and H. X. Wang. (2016). "Experimental study on slow flexural waves around the defect modes in a phononic crystal beam using fiber Bragg gratings," Phys. Lett. Sect. A Gen. At. Solid State Phys., vol. 380, no. 47, doi: 10.1016/j.physleta.2016.09.055.

[14] Coote, J. M., Torii, R., \& Desjardins, A. E. (2021). Dynamic Characterisation of FibreOptic Temperature Sensors for Physiological Monitoring. Sensors, 21(1), 221.

[15] Ding, Z., Tan, Z., Gao, Y., Wu, Y., \& Yin, B. (2020). Strain and temperature discrimination using a fiber Bragg grating concatenated with PANDA polarizationmaintaining fiber in a fiber loop mirror. Optik, 221, 165352..

[16] Sarkar, S., Tarhani, M., Khosravi Eghbal, M., \& Shadaram, M. (2020). Discrimination between strain and temperature effects of a single fiber Bragg grating sensor using sidelobe power. Journal of Applied Physics, 127(11), 114503. 